\title{
Fracture of the Penis: About a Case of Delay in Management at the Nianankoro Fomba Hospital in Segou-Mali
}

\author{
Sory I. Kone'1*, B. Samake², M. Keita², T. B. Bagayoko3 , A. Bah4, A. Kassogue ${ }^{4}$, A. Sanogo5, \\ A. N. Coulialy6, M. Togo6 ${ }^{6}$ D. Coulibaly 7 , T. Traore ${ }^{8}$, A. Fofana ${ }^{9}$ \\ ${ }^{1}$ Urology Department, Nianankoro Fomba Hospital, Segou, Mali, \\ ${ }^{2}$ General Surgery Department, Nianankoro Fomba Hospital, Ségou, Mali \\ ${ }^{3}$ Forensic and Occupational Medicine Department, Nianankoro Fomba Hospital, Ségou, Mali \\ ${ }^{4}$ Pediatrics Department, Nianankoro Fomba Hospital, Ségou, Mali \\ ${ }^{5}$ Cardiology Department, Nianankoro Fomba Hospital, Ségou, Mali \\ ${ }^{6}$ Ophthalmology Department, Nianankoro Fomba Hospital, Ségou, Mali \\ ${ }^{7}$ Internal Medicine Department, Nianankoro Fomba Hospital, Ségou, Mali \\ ${ }^{8}$ Obstetrics and Gynaecology Department, Nianankoro Fomba Hospital, Ségou, Mali \\ ${ }^{9}$ ENT Department, Nianankoro Fomba Hospital, Ségou, Mali \\ Email: *sorykone72@gmail.com
}

How to cite this paper: Kone, S.I., Samake, B., Keita, M., Bagayoko, T.B., Bah, A., Kassogue, A., Sanogo, A., Coulialy, A.N., Togo, M., Coulibaly, D., Traore, T. and Fofana, A. (2022) Fracture of the Penis: About a Case of Delay in Management at the Nianankoro Fomba Hospital in Segou-Mali. Open Journal of Urology, 12, 136-145.

https://doi.org/10.4236/oju.2022.122014

Received: November 13, 2021

Accepted: February 15, 2022

Published: February 18, 2022

Copyright $\odot 2022$ by author(s) and Scientific Research Publishing Inc. This work is licensed under the Creative Commons Attribution International License (CC BY 4.0).

http://creativecommons.org/licenses/by/4.0/

(c) (i) Open Access

\begin{abstract}
Introduction: Fracture of the penis is a rare uro-andrological emergency defined as the rupture of the tunica albuginea of the erect penis most often during sexual intercourse. Surgical exploration and repair of the albuginea breach as soon as possible are the standard treatment. However, in our African context, early diagnosis and management are negatively influenced by the delay in consultation due to modesty. Our objective was to describe the clinical and therapeutic aspects of the fracture of the penis seen late in the African context and to compare it with the literature review. Presentation of the case: Our aim was to report our experience in the management of late-onset fracture of the penis, after more than 48 hours of evolution, by reporting the observation of a 54-year-old patient, who had a false coitus, treated in the urology department of the Nianankoro Fomba Hospital. The physical examination revealed a deformation of the penis following the formation of a large hematoma with a characteristic eggplant appearance. Therapeutically, a suture of the albuginea was performed with simple follow-up. Conclusion: This case study shows a delay in the management of this emergency due to the reluctance of the patient to be consulted as soon as possible for reasons of modesty. A delayed emergency surgical management was the only therapeutic alternative and the coronal incision with degloving was the only way to ap-
\end{abstract}


proach the voluminous hematoma related to the delay in management.

\section{Keywords}

Penis, Fracture, Corpora Cavernosa, Albuginea, Nianankoro Fomba Hospital

\section{Introduction}

Fracture of the penis is a rare uro-andrological emergency defined as the rupture of the tunica albuginea of the erect penis most often during sexual intercourse.

The main cause is the coital faux pas, where the erect penis strikes the pubic symphysis or the partner's perineum [1]. The diagnosis of a fracture of the penis is based on a typical clinical presentation associating a rapid detumescence of the penis, the formation of a hematoma, a cracking sound and a deformation of the penis. Urethral involvement must be systematically sought during the clinical examination in search of macroscopic or microscopic hematuria or acute retention of urine. In case of diagnostic doubt or before performing an elective approach, imaging should be performed, with penile MRI or ultrasound as the first option.

Surgical exploration and repair of the albuginea breach as soon as possible are the reference treatment with possibly an elective approach for trained operators in the case of a clearly localized fracture line. The coronal incision with degloving is the reference approach allowing a complete exploration with an associated lesion assessment despite the more important postoperative complications. The surgical treatment consists of evacuating the hematoma, performing hemostasis, trimming and suturing the tear of the albuginea. A lesion of the urethra should be sought and sutured if present [1]. The management of a fracture of the penis must be done as a matter of urgency; however, in Mali, modesty has a negative impact on the arrival of certain patients in health facilities.

Our aim was to report our experience in the management of a fracture of the penis after more than 48 hours of evolution by reporting the observation of a patient treated in the urology department of the Nianankoro Fomba Hospital. Our objective was to describe the clinical and therapeutic aspects of the fracture of the penis in the African environment and to compare it with the literature review.

\section{Observation}

We report a case of fracture of the penis after 48 hours of evolution in a 54-year-old patient. The patient, married, polygamous and father of 6 children, was referred from a referral health center that had received him 48 hours after the accident. Upon admission to the hospital the next day, the interrogation revealed the notion of sexual intercourse.

The patient would have made a false step of coitus with reception of the penis 
in erection on the pubis of the spouse, he would have heard a cracking followed by the immediate loss of the erection with installation of a sharp pain and a swelling of the genitals for which he took an anti inflammatory without success. No particular history was found in the patient.

I On physical examination a Peno scrotal edema was found with characteristic appearance of eggplant penis (Figure 1).

The Rolling Sign was negative.

A Doppler ultrasound of the corpora cavernosa showed on a longitudinal section, an irregularity of the left corpora cavernosa at the median level of the penis, a spongy body on both sides of the urethra of homogeneous structure (Figure 2).

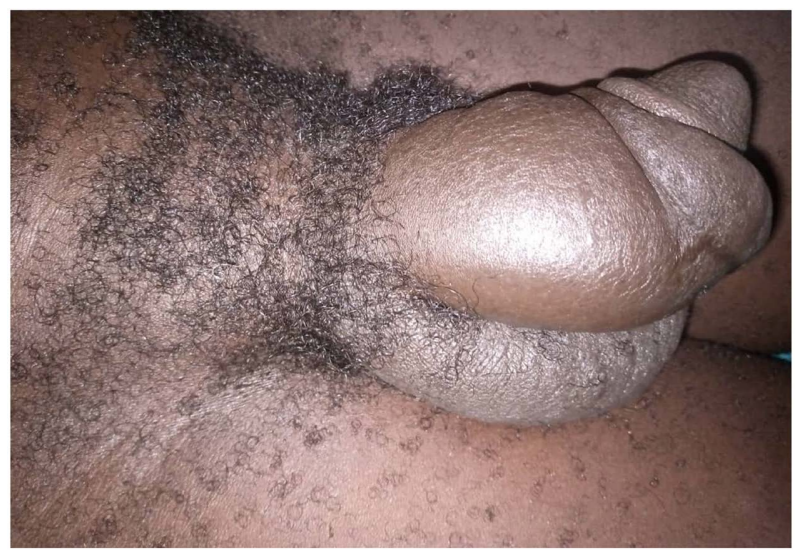

Figure 1. Appearance of the eggplant penis.
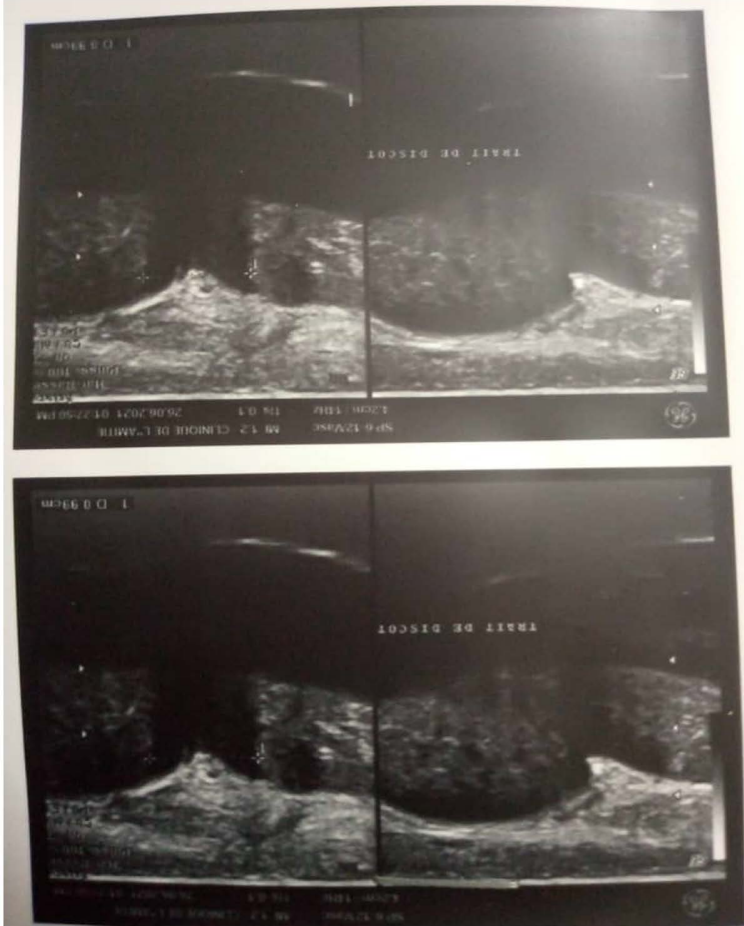

Figure 2. Ultrasound result. 
The blood count (CBC) came back normal.

The coagulability test was normal.

The patient was grouped $\mathrm{B}+$ (positive).

Therapeutic management was surgical. However, certain prerequisites were taken into account, such as the use of an ice bladder, a lightly compressive bandage, antibiotic prophylaxis and ketoprofen-based anti-inflammatory treatment.

For the surgical treatment, the patient was placed in dorsal decubitus position under locoregional anesthesia (spinal anesthesia).

We proceeded to a coronal incision, to a degloving to the root of the penis (Figure 3).

Exploration revealed a haematoma which was evacuated by a longitudinal incision of Buck's fascia, exposing a breach of the albuginea of the left corpora cavernosa measuring $20 \mathrm{~mm}$, the urethra was found to be free of lesions (Figure 4, Figure 5).

The procedures performed were evacuation of the hematoma, lavage with saline and suturing of the albuginea in separate stitches with 3/0 vicryl (Figure 6, Figure 7).

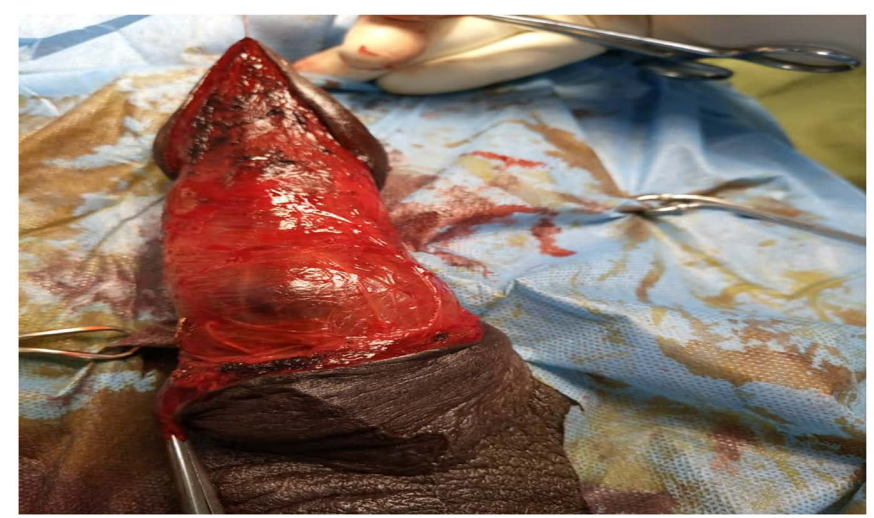

Figure 3. Operative view of the removal of the penis.

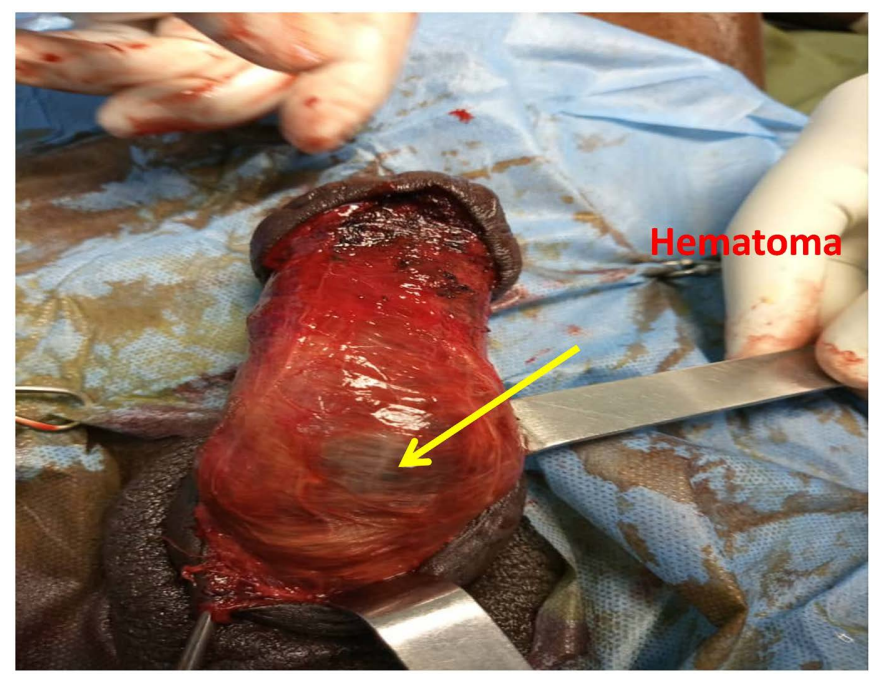

Figure 4. Surgical view of the hematoma. 


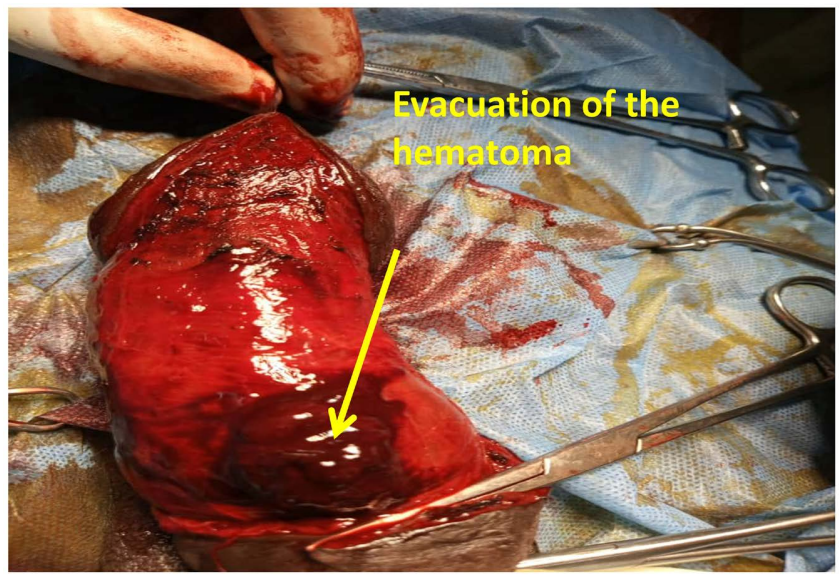

Figure 5. Surgical view of the evacuation of the hematoma.

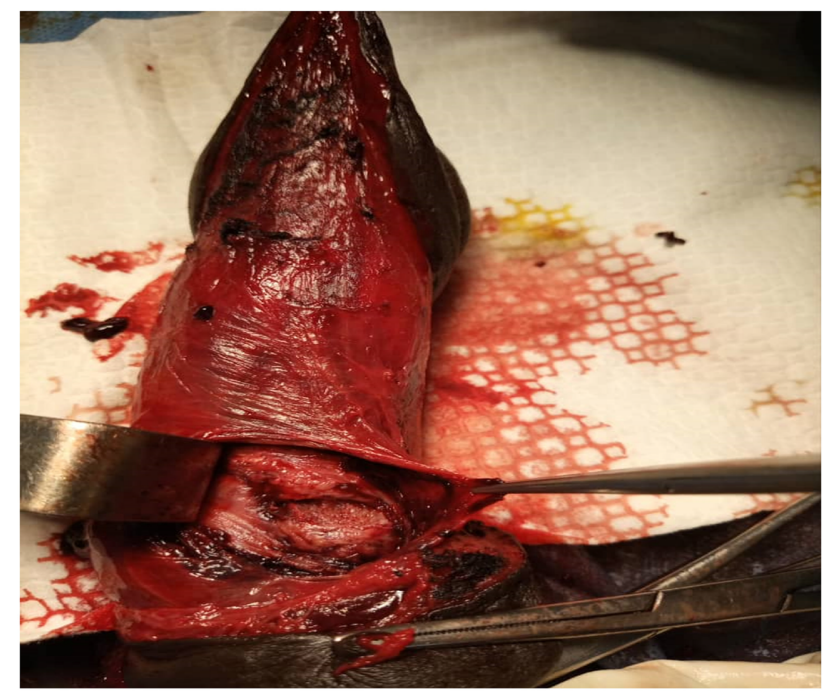

Figure 6. Surgical view of the breach of the albuginea of the corpus cavernosum.

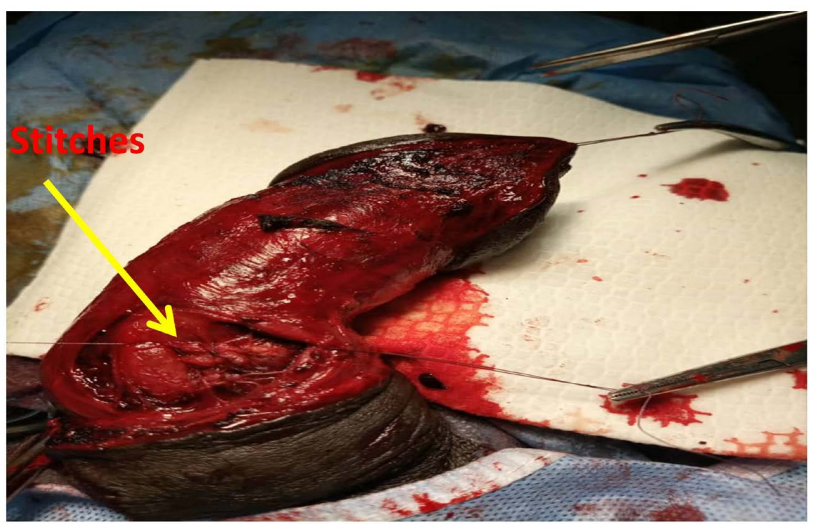

Figure 7. Suture of the albuginea breach of the corpus cavernosum.

We then performed an overjet suture of Buck's fascia with 3/0 Vicryl and a coronal suture in separate points with $2 / 0$ Vicryl. The immediate postoperative course was simple (Figure 8). 


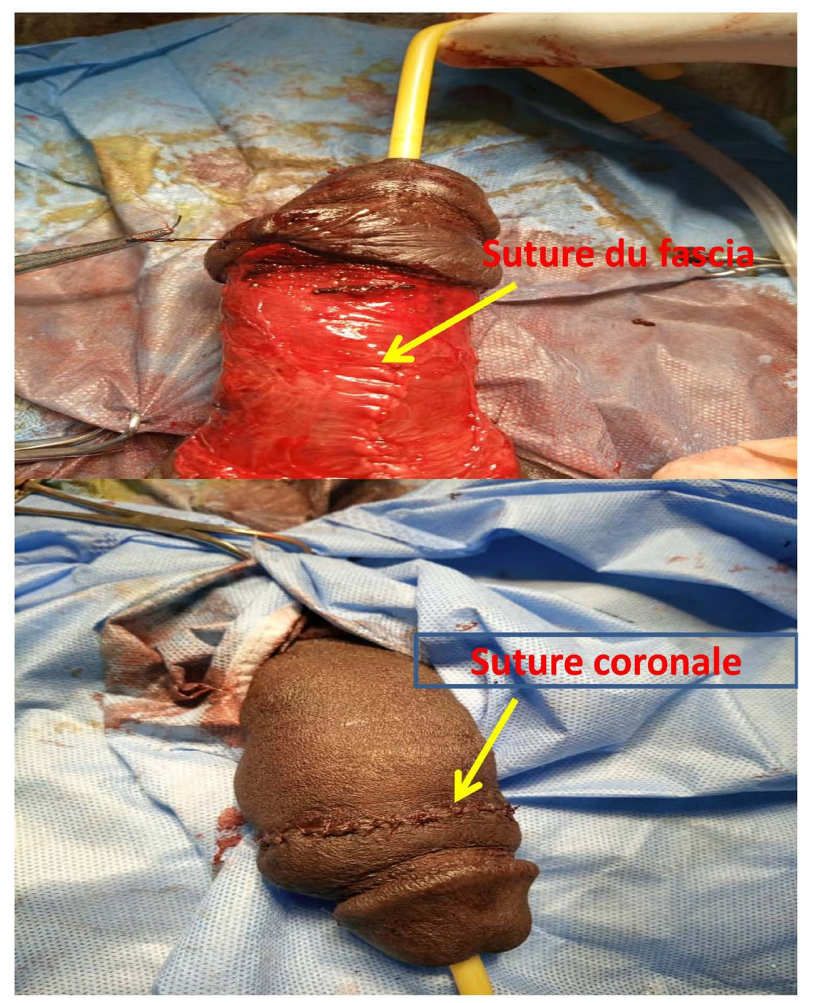

Figure 8. Surgical view of closure (Buck's fascia suture and coronal suture).

An anti-androgenic treatment (androcur) was instituted for one month in order to avoid the physiological nocturnal erection before healing as well as an analgesic and anti-inflammatory treatment (Figure 9).

The patient was seen again three months after the operation, without any particular sign and with a preserved erection (Figure 10).

\section{Discussion}

\subsection{Hospital Frequency}

The extreme rarity of this accident in our context, which is evidenced by the reporting of only one case in 9 years (from October 2013 to September 2021) is probably related to the under-reporting of cases. For reasons of modesty, a certain number of patients tend to want to conceal the accident and therefore do not come to the care structures.

They generally resort to traditional therapies. Socio-cultural aspects in the African environment make everything related to sex a taboo subject. This is a limiting factor for care. Previous studies have noted the negative interference of this modesty leading to an underestimation of the hospital frequency of fracture of the penis [2] [3] [4]. In 66 years, Eke et al in a review of the literature counted 1331 cases reported by 183 publications worldwide [5].

Age: Our patient, 54 years old, is relatively older than those reported in several previous studies. One of the series reported a mean age of the patients estimated at 38.3 years with extremes of 30 and 43 years [3]. 


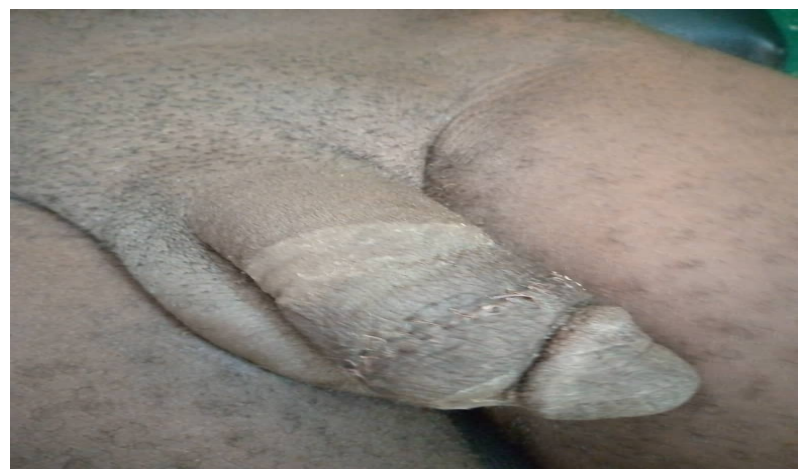

Figure 9. Postoperative result on day 9.

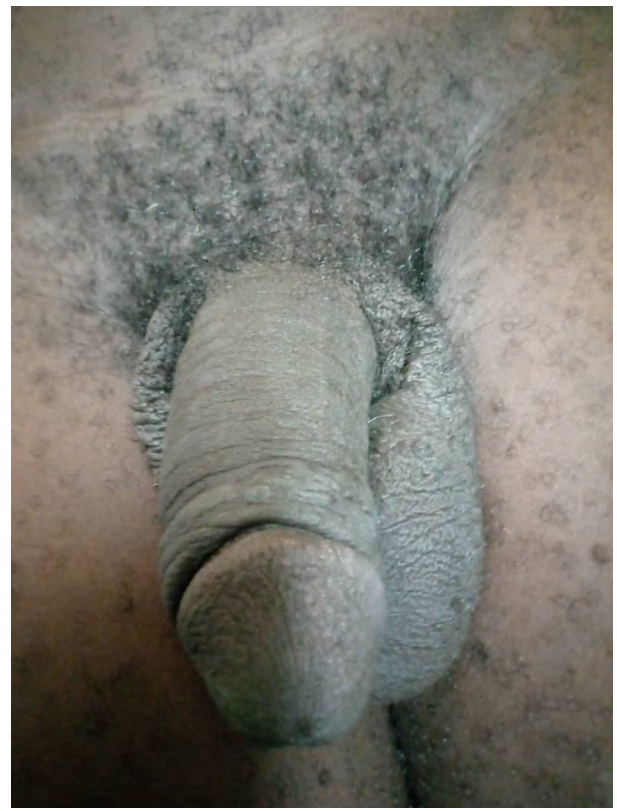

Figure 10. View of the penis at 30 days post-op.

The pathology is recognized as a condition that affects mainly young and sexually active adults [2] [4] [6].

\subsection{Etiology or Mechanism}

In our patient it was a coitus faux pas. This is the most frequent cause in the western literature [7] [8] as well as in previous studies in Mali and in the sub-region. However, in the Middle East, coital malpractice is second only to untimely manipulation of the erect penis during masturbatory maneuvers, turning over in bed during sleep, or straightening up and concealing a morning erection in a promiscuous context [9] [10].

\subsection{Management}

The delay in management, which was more than 48 hours in our patient, was relatively long given the urgent nature of the case. This delay in requesting a consultation was related to modesty in our patient. A relatively long average de- 
lay of 74 hours has been reported in a previous series. According to the authors, this delay in management was related to the reluctance of patients to consult for this reason, which is generally difficult to mention in Africa because of the modesty of the population [2] [3].

In our case, the diagnosis was made on the basis of clinical findings, although a Doppler ultrasound of the penis was performed to evaluate the lesion before surgery. The diagnosis was made after sexual intercourse with an audible cracking sound when the erect penis was accidentally landed on the partner's pubic bone, and significant edema of the penis with the characteristic appearance of an eggplant penis. In the literature the diagnosis of the fracture of the penis is clinical [11] [12] [13] [14]. Ultrasound and magnetic resonance imaging (MRI) are often used but are not essential [15] [16].

The management of our patient was surgical in accordance with the trend in the literature, the conservative treatment being more and more abandoned because of its complications. A coronal incision was made with degloving of the penis and suturing of the albuginea breach in our patient. The postoperative course was simple in our patient. This type of incision allows for better exploration and a complete lesion assessment. In addition, the scar is more aesthetically pleasing, unlike longitudinal lateral incisions opposite a corpus cavernosum, allowing an elective approach to the fracture site.

In our case, an elective approach was not possible, despite the proximal location of the fracture site, because of a large hematoma of the penis in our patient. A coronal incision with degloving was necessary in our patient because of the hematoma, which had become large due to the delay in management. In the literature, an elective approach is possible when the fracture zone is proximal and clearly identified clinically or radiologically; it is not feasible in cases of large hematoma. An incision opposite this area allows for elective repair without the need to undress the entire penis, thus shortening the operating time and making it simpler for teams not used to degrafting.

Moreover, studies have shown a lower morbidity in terms of infection, abscesses and skin necrosis in small series ( $10 \%$ to $24 \%$ of complications) [17]. The literature as a whole agrees on the need for emergency treatment as soon as possible, ideally within 24 hours, to avoid serious functional repercussions. Delayed surgical treatment is also recommended in cases of delayed consultation (even beyond 48 hours), according to the same surgical principles but with a higher risk of pseudoaneurysmal hematoma and postoperative complications [8].

In front of the physiological erections in our patient postoperatively, we had to use an inhibitory treatment however some authors did not advocate an erection inhibiting treatment considered unnecessary [1].

\section{Conclusion}

The fracture of the penis is an emergency, however in our context the modesty 
impacts negatively the delay of surgical management imposing then the surgery in emergency deferred, the conservative treatment being less and less proposed nowadays [1].

\section{Acknowledgements}

The authors thank the patient who kindly gave his informed consent and took part in this study.

\section{Conflicts of Interest}

The authors declare no conflicts of interest regarding the publication of this paper.

\section{References}

[1] Kara, N., Jounel, N.M., Ruffision, A. and Terrier, J.-E. (2005) When and How to Operate on Fractures of the Penis. Progres en urologie FM 2005,3,2,5,F73.

[2] Diarra, A., Mohamed Ali, M.A., Kassogue, A., Keita, M.M., Coulibaly, M. and Berthe, H.J.G. (2019) Fracture of the Penis about 2 Cases at the Urology Department CHU Luxembourg. Mali medical 2019 Tome XXXIV.

[3] Paré, A.-K., Ouattara, A., Botcho, G., Kirakoya, B., Kaboré, F.A., Bako, A., Yé, D., Bayané, D., Konaté, M. and Kambou, T. (2019) The Fracture of the Penis CHU at Sanousouro de Bobo-Dioulasso, Burkina Faso. The Pan African Medical Journal, 33, 257. https://doi.org/10.11604/pamj.2019.33.257.19452

[4] Nachagande, G., Avakadjo, J.D.G. and Gandaho, K.I. (2013) Fracture of the Penis at the University Clinic of Urology of Cotonou Medicine of Black Africa. (6009): 368-372.

[5] Eke, N. (2002) Fracture of the Penis. British Journal of Surgery, 89, 555-565. https://doi.org/10.1046/j.1365-2168.2002.02075.x

[6] Barry II, M., Kante, D. and Diallo, T.M.O. (2016) Fracture of the Penis: Retrospective Analysis of 22 Cases in the Urology Department of the Ignace Deen Hospital, CHU of Conakry Guinea Uro-AndroHome Page. Vol. 1, No. 6 > BARRY.

[7] Nason, G.J., McGuire, B.B., Liddy, S., Looney, A., Lennon, G.M., Mulvin, D.W., et al. (2013) Sexual Function Outcomes Following Fracture of the Penis. Canadian Urological Association Journal, 7, 252-257. https://doi.org/10.5489/cuaj.199

[8] Yamaçake, K.G., Tavares, A., Padovani, G.P., Guglielmetti, G.B., Cury, J., Srougi, M., et al. (2013) Long-Term Treatment Outcomes between Surgical Correction and Conservative Management for Penile Fracture: Retrospective Analysis. Korean Journal of Urology, 54, 472-476. https://doi.org/10.4111/kju.2013.54.7.472

[9] Nawaz, H., Khan, M., Tareen, F.M. and Khan, S. (2010) Penile Fracture: Presentation and Management. Journal of College of Physicians and Surgeons Pakistan, 20, 331-334.

[10] Al-Samaraee, J.A.A. (2005) A Study on Fracture Penis in Sallah Al-Deen Province (Personal Experience). Tikrit Medical Journal, 112, 44-46.

[11] Raza, M.K., Masud, A.M., Muhammad, J., Delawar, K. and Iftikhar, H.S. (2008) Penile Fracture: Experience at Ayub Teaching Hospital. Journal of Ayub Medical College Abbottabad, 20, 49-50.

[12] Rimtebaye, K., Danki, S., Ndoye, M. and Vadandi, V. (2015) Fracture de la verge, 
aspects cliniques et prise en charge, a propos de 14 cas penile fracture in chad, clinical and therapeutic aspects: report of 14 cases. URO'ANDRO, Volume 1, No. 3, Janvier.

[13] Diallo, K.M.S., Coulibaly, S., Cisse, D., Tembely, A. and Ouattara, Z. (2018) Fracture of the Penis with Complete Rupture of the Urethra Medecine of Black Africa. Vol. 65, No. 5.

[14] Kpatcha, T.M., Tengue, K., Botcho, G., Sikpa, K.H., Léloua, E., Sewa, E.V., Amegayibor, O., Anoukoum, T. and Dosseh, E.D. (2017) Our Experience in the Management of Penile Fracture at the University Hospital of Lomé Our Experience in the Management of Penile Fracture. African Journal of Urology, 23, 342-346.

[15] Pruthi, R.S., Petrus, C.D., Nidess, R. and Venable, D.D. (2000) Penile Fracture of the Proximal Corporeal Body. The Journal of Urology, 164, 447-448.

https://doi.org/10.1016/S0022-5347(05)67386-7

[16] Uder, M., Gohl, D., Takahashi, M., et al. (2002) MRI of Penile Fracture: Diagnosis and Therapeutic Follow-Up. European Radiology, 12, 113-120. https://doi.org/10.1007/s003300101051

[17] Mansi, M.K., Emran, M. and el-Mahrouky, A. (1993) el-Mate et M.S. Experience with Penile Fractures in Egypt: Long-Term Results of Immediate Surgical Repair. The Journal of Trauma, 35, 67-70. https://doi.org/10.1097/00005373-199307000-00011 